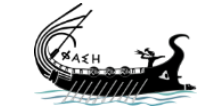

journal.phaselis.org
PHAS LLIS

Issue IV (2018)
Disiplinlerarası Akdeniz Araştırmaları Dergisi

Journal of Interdisciplinary Mediterranean Studies

\title{
Phaselis Güney Limanı
}

Phaselis' South Harbor

\author{
Erdoğan ASLAN - Yusuf KILIÇ - Uğurcan ORHAN
}

open 2 access journals

The entire contents of this journal, Phaselis: Journal of Interdisciplinary Mediterranean Studies, is open to users and it is an 'open access' journal. Users are able to read the full texts, to download, to copy, print and distribute without obtaining the permission of the editor and author(s). However, all references to the articles published in the e-journal Phaselis are to indicate through reference the source of the citation from this journal.

Phaselis: Journal of Interdisciplinary Mediterranean Studies is a peer-reviewed journal and the articles which have had their peer reviewing process completed will be published on the web-site (journal.phaselis.org) in the year of the journal's issue (e.g. Issue III: JanuaryDecember 2017). At the end of December 2016 the year's issue is completed and Volume IV: January-December 2018 will begin.

Responsibility for the articles published in this journal remains with the authors.

Citation E. Aslan, Y. Kılıç, U. Orhan, "Phaselis Güney Limanı". Phaselis IV (2018) 1-13. http://dx.doi.org/10.18367/Pha.18001

Received Date: 22.12.2017 | Acceptance Date: 18.01.2018

Online Publication Date: 13.02.2018

Editing Phaselis Research Project

www.phaselis.org 


\title{
Phaselis Güney Limanı
}

\author{
Phaselis' South Harbor
}

Erdoğan ASLAN* Yusuf KILIÇ** Uğurcan ORHAN**

Öz: Kıyı kentlerinin yaşam kaynağı olan antik liman alanlarındaki çalışmalar son yıllarda artış göstermektedir. Birden fazla limanı bulunan Phaselis antik kentinde bu çalışmaların yoğunlaşması kentin öneminin anlaşılmasında temel bir gerekliliktir. Akropolisin batısında oldukça korunaklı bir demirleme alanı olan Güney Liman Alanı ve mimari yapıları bu çalışmamızın konusunu oluşturmaktadır. Liman alanında, mendirek, iskele, kıyı yapıları ve bu yapılara ait birçok blok sualtında dağınık halde bulunmaktadır. Liman alanı güney sınırında uzanan yapay dolgu üzerinde temel seviyesinde takip edilen mendirek ile liman içerisindeki yapıların ilişkisi ve yapılan düzenlemelerin tarihlendirilmesi bu makalede cevaplanması gereken temel soru olarak ele alınmıştır. Arkaik Dönem’den Geç Antik Çağ’a kadar kullanıldığı düşünülen liman alanının evrelerinin tespiti ve tarihlendirilmesi, bu makalede yer verilen mimari kalıntıların değerlendirilmesiyle gerçekleştirilmiştir. Çalışma kapsamında haritalandırma, havadan ve sualtından görüntüleme cihazları kullanılarak bu verilerin net bir şekilde belgelenmesi, kentin dış dünyaya açılan kapısı niteliğindeki liman alanını diğer örneklerle karşılaştırarak yorumlayabilmemize olanak sağlamaktadır.

Anahtar sözcükler: Phaselis, Liman Mimarisi, Güney Liman, Mendirek, Sualtı, Pamphylia

Abstract: Studies in the ancient harbor areas, which are the sources of life for coastal cities, have increased in recent years. The concentration of these works in the Phaselis Ancient City, which has more than one port, is a fundamental requirement for understanding the city. South Harbor Area, which is a very sheltered anchoring area to the west of the Acropolis and architectural structure, constitutes the subject of our work. Port area, breakwater, pier, coastal structures and many blocks belonging to this structure are scattered underwater. The relationship between the breakwater which on the ground level on the artificial filling lying on the south border of the port area and the structures inside the harbor and the arrangements made in the harbor area are considered as the basic problem to be answered in this article. The determination and the dating of the phases of the harbor area thought to have been used from the Archaic to the Late Antiquity was carried out by evaluating architectural remains in this article. Within the scope of the study, the documentation of these data using mapping, aerial and underwater imaging devices allows the city to compare the port area of the gateway to the outside world with other examples.

Keywords: Phaselis, Harbour Architecture, South Harbour, Jetty, Underwater, Pamphylia

* Doç. Dr., Selçuk Üniversitesi, Edebiyat Fakültesi, Arkeoloji Bölümü, Konya, erdoganaslan@gmail.com

** PhD., Ankara Üniversitesi, Dil-Tarih ve Coğrafya Fakültesi, Arkeoloji Bölümü, Ankara, yusuffkilicc@gmail.com

*** MA., Selçuk Üniversitesi, Edebiyat Fakültesi, Arkeoloji Bölümü, Konya, orhanugurcan@gmail.com Bu makalenin konusunu oluşturan çalışma, Selçuk Üniversitesi Bilimsel Araştırma Projeleri Koordinatörlüğü’nün 17401021 nolu "Phaselis Antik Kenti Liman ve Sualtı Araştırmaları" başlıklı araştırma projesi kapsamında maddi ve ayni olarak desteklenmiştir. 


\section{Giriş}

Mal alım ve değişimi için farklı kültürlerin bir araya geldiği limanlar ${ }^{1}$ kültür değişimlerinin de odak noktası olarak tarihsel önem taşımaktadır. Strabon, Likya sahilinin engebeli ve geçilmesi zor olmasına rağmen son derece iyi donatılmış limanlara sahip olduğunu bildirmektedir ${ }^{2}$. Gelidonya ${ }^{3}$ ve Ulu Burun' da ${ }^{4}$ iki gemi enkazının bulunması, Bronz Çağ'ın sonlarına doğru Likya sahili boyunca işlek bir denizciliğin varlı̆ıını belgelemektedir. Sonraki dönemlerde, İskenderiye'den gelen tahılın Likya'nın liman kentlerinden Patara'da ve Andriake'de geçici olarak depolanması için muazzam büyük tahıl depolarının (granarium'lar) yapılması tesadüf olmamalıdır ${ }^{5}$. Likya'dan ihraç edilen sünger, sandal, sedir ${ }^{6}$ ve erguvan renkli salyangozlar (Purpureai Chelidoniae) gibi ticari malların antikçağda oldukça ünlü olduğu bilinmektedir ${ }^{7}$. Ticaret ve denizciliğin gelişmesiyle iç kısımda yer alan kentler giderek değer kaybetmiş, politik merkez sahile taşınmıştır. Arkeolojik buluntuların da gösterdiği gibi Likya limanlarının önemi Hellenistik Dönem’de artmıştır ${ }^{8}$. Akdeniz ticareti için önemli bir noktada bulunan Likya bölgesi bu konumundan dolayı MÖ II. bin yıldan itibaren önemli bir deniz gücüne de sahip olmuştur ${ }^{9}$. Bölgede MÖ II. ve I. yüzyılda devam eden korsan faaliyetleri yüzünden Akdeniz ticareti huzursuz bir dönem geçirmiştir ${ }^{10}$. Kilikya ve Pamphylia'nın liman kentlerinden pek çoğu korsanlarla işbirliği yaparken Likya'da Olympos, Korykos ve Phaselis dışında hiçbir kent korsanlarla işbirliği yapmamıştır ${ }^{11}$. Bütün bunlar Likya limanlarının ve denizciliğinin Akdeniz'de oynadığı önemli rolü açıkça ortaya koymaktadır. Tarih boyunca Anadolu kıyılarında görülen deniz seviyesi değişimleri ve tektonik hareketler de ayrı bir başlık olarak arkeolojik sualtı çalışmalarının gerekliliğini kanıtlamaktadır. Bu sayede elde edilen verilerin daha geniş perspektiften değerlendirilmesi mümkün olabilir.

Günümüzde Antalya ili, Tekirova İlçesi, Pamphylia Körfezi'nin batı sahilinde yer alan ve üç liman alanı ${ }^{12}$ olan Phaselis kentinde, limanların Arkaik Dönem'den Geç Antik Çağ’a kadar kullanıldığı anlaşılmaktadır ${ }^{13}$ (Fig. 1). Kentin denizcilik tarihinde birçok olayda adının geçmesi önemli deniz rotaları üzerinde bulunmasından kaynaklanmaktadır ${ }^{14}$. Antik kaynaklar tarandı-

1 Zimmermann 1992b, 168

2 Strabon (XIV. 3. 2) "1700 stadia uzunluğunda olan bu kıyı şeridi oldukça dağlıktır ve zor geçit verir; ama sık bir biçimde iyi limanlarla donatılmış ve nezih bir halk tarafından iskân edilmiştir" şeklinde aktarmaktadır.

3 Kap Gelidonya batığı asıl olarak bakır, bronz ve kalay külçeleri ve de bronz av saçması taşıyordu ve MÖ XIII. yüzyılın ikinci yarısında ya da MÖ XII. yüzyılın ilk yarısında batmıştı. Bkz. Bass 1961, 271; Bass et al. 1967, 1-177.

4 Ticari malların yanında büyük miktarda metal taşıyan gemi Gelidonya batığından yaklaşık iki yüzyıl daha erkene tarihlenebileceği düşünülmektedir. Ayrıca bk. Bass 1986, 269-296.

5 Balland 1981, 217; Zimmermann 1992b, 223, 225; Foss 1994, 14, 25.

6 Bölgede kaliteli sedirlerin yetiştiğinden bahsedilmektedir. Bkz. Plin. nat. XII. 132, XIII. 52-53, XVI. 137; ayrıca bk. Magie 1950, 518, 1372.

7 Jameson 1973, 288; Zimmermann 1992a, 201; Aygın 2017, 1 vd.

8 Teimussa limanındaki küçük klasik kale bu dönemde modernleştirilmiştir. Aperlai ve Phaselis'in kent duvarları ve belki de Olympos rıhtımı da bu döneme aittir. Bkz. Kolb-Kupke 1992, 54.

9 Bryce 1986, 5; Frei 1993, 87 vd.; ayrıca bk. Arslan 2018, 2 vd.

10 Arslan 2003a, 91 vd.; Arslan - Tüner-Önen 2011, 193.

11 Marek 1995, 17 vd.; Tüner-Önen 2008, 10-12.

12 Antikçağ liman kentleri arasında nadir olarak görülen üç limanlı Amastris, Piraeus gibi kentlerin varlığı bilinmekle birlikte, Strabon'un göl olarak tanımladığı bataklık alanı da erken dönem liman alanlarından biri olmalıdır. Bkz. Lehmann- Hartleben 1923, plan XX; Blackman 1982, 189, Fig. 3; Aslan - Baybo 2015, 13, dn 46.

13 Kent tarihi hakkında ayrıntılı bilgi için bkz. Tüner-Önen 2012a, 206 vd.; Tüner-Önen 2012b, 479 vd.; Aslan Baybo 2015, 2-4; Aslan 2016a, 31.

14 Tüner-Önen 2008, 17, 57, 63, 68, 97, 131; Arslan 2012, 251; Seyrig 1963, 39 vd.; Robert 1966, 45; HeippTamer 1993, 52, 58, 64, 76; Müller 2010, 427 vd.; Beaufort 2002, 55, 58. Daha detaylı bilgi için ayrıca bk. 
ğında liman alanlarından en detaylı şekilde Strabon'un bahsettiği görülmektedir ${ }^{15}$.

Modern araştırmalara bakıldığında ise kent limanları hakkında verilen bilgilerin sayı, konum ve korunan bazı kııımlar ile sınırlı kaldığ ${ }^{16}$, fakat özellikle son yıllarda yapılan araştırmalarla ${ }^{17}$ liman alanlarının; işlevi, kent tarihindeki önemi, inşa ve yıkılış tarihlerinin analiz edildiği görülmektedir $^{18}$. Askeri amaçlar doğrultusunda kullanıldığı bilinen İç Liman, Hellenistik sur ile çevrili kent limanı ve ticaret gemileri tarafından bekleme alanı olarak kullanılmış olabileceği ileri sürülen Kuzey Demirleme Alanları'nda yapılan çalışmalar bilimsel yayın olarak sunulmuştur ${ }^{19}$. Bu makale ile ticari fonksiyonunun ön planda olduğu düşünülen Güney Liman Alanı'nın; tarihi, gelişim evreleri ve kullanım sürecinin güncel araştırmalar ışığında saptanması amaçlanmıştır. Bu amaç doğrultusunda Güney Liman Alanı; I. Güney Liman Mendireği, II. Güney Liman Alanı İskele Yapıları, III. Güney Liman Kıyı Yapıları alt başıkları altında değerlendirilmiştir.

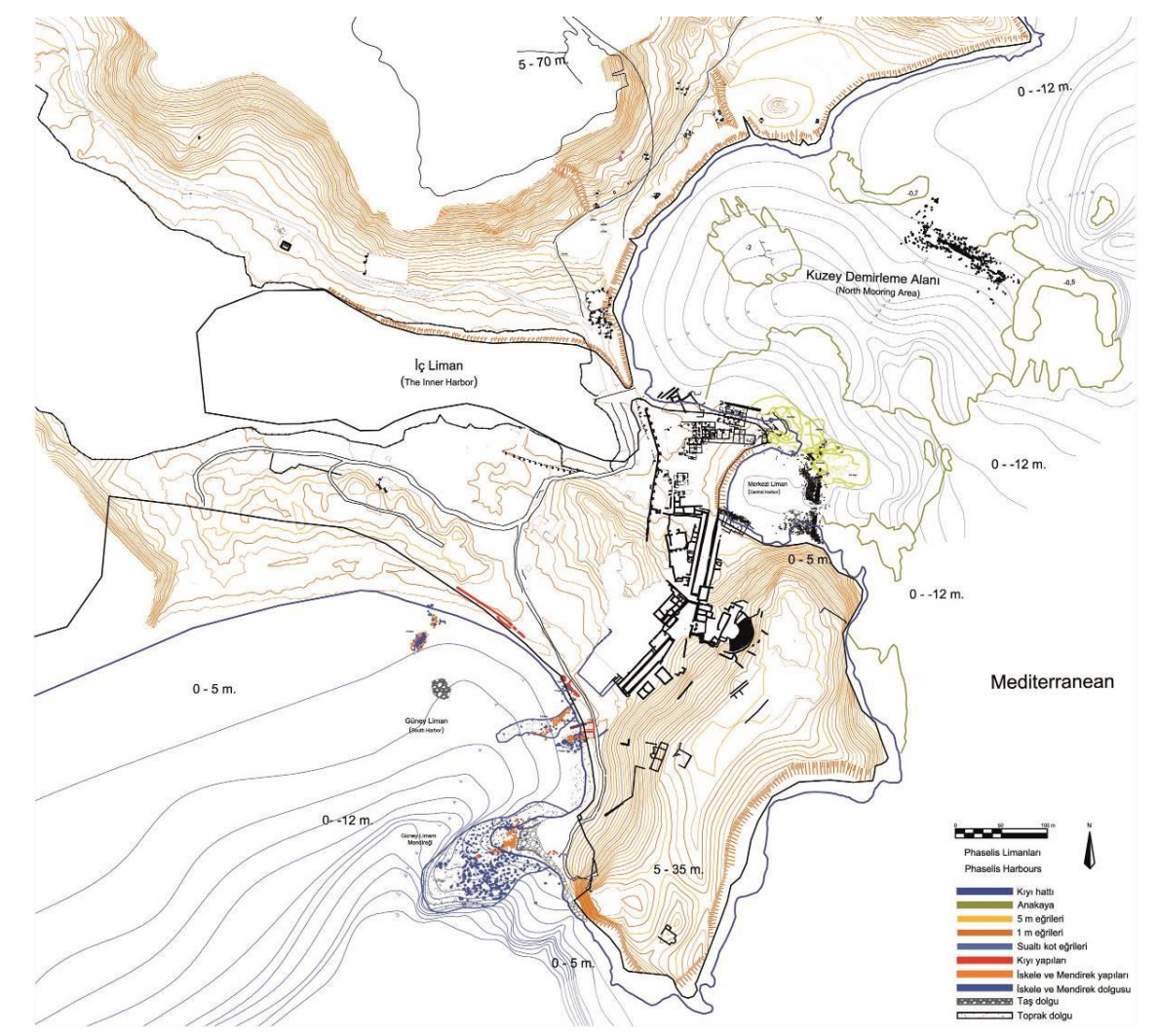

Figür 1. Phaselis kent planı

Thuk. II. 69; Plut. Aleks. XVII. 8; Strab. XIV. 3. 9, 5. 7; Liv. XXXVII. 22; ayrıca bk. Schäfer et al. 1981, 33; Arslan 2003a, 91, 93; Arslan 2003b, 199; Arslan - Tüner-Önen 2011, 191, dn. 16. Strab. XIV. 3. 9.

16 Lehmann-Hartleben 1923, 20, 276; Stark 1956, 172 vd.; Bean 1968, 151 vd.; Schläger- Schäfer 1971, 254 vd.; Blackman 1973, 335 vd.; Schäfer et al. 1981, 1, 13 vd.; Beaufort 2002, 58; Tüner-Önen 2008, 67-73; Arslan et al. 2013, 224; Arslan - Tüner-Önen 2013, 78 vd.

172013 yılından itibaren Prof. Dr. Murat Arslan başkanlığında sürdürülen Phaselis Antik Kenti ve Teritoryumu Yüzey Araştırmaları kapsamında, Doç. Dr. Erdoğan Aslan tarafından Phaselis Limanları ve çevresine yönelik arkeolojik su altı çalışmaları yürütülmektedir.

18 Aslan - Baybo 2015, 4 vd. 6; Aslan 2016a, 31 vd.

19 Aslan - Baybo 2015, 7; Aslan 2016a, 31-47. 


\section{Güney Liman Alanı}

Doğal konumu ve yapay mendirek alanı ile oldukça korunaklı hale gelen güney liman kent akropolisin güneybatısında, körfezin doğu kısmında yer almaktadır (Fig. 1-3). Limanın batısındaki yüksek tepeler bölgede hâkim olan batı rüzgârlarını keserken, özellikle kış aylarında güneyden esen şiddetli rüzgârlar için mendirek inşa edildiği görülmektedir. Korunaklı yapısına ek olarak kuzeydeki gibi sığ ve kayalıklarla kaplı olmayışı, liman alanının havzası, çevresindeki yapılaşma, konumu ve benzer örnekleri ile bu limanın ticari faaliyetlerde kullanıldığına ilişkin göstergelerdir ${ }^{20}$.

Güney Limanı'nın havzasının kuzeybatı ve batı bölümü günümüzde ince kumlu bir sahil şerididir. Kıyı hattı boyunca batıda herhangi bir yapı kalıntısı görülmezken, doğuda iki, kuzeyde bir olmak üzere toplam üç adet iskele kalıntısı ve yine doğuda üç, kuzeyde bir adet olmak üzere toplam dört adet yapı kalıntısı bulunmaktadır. Rıhtım yapılarının bulunması gereken limanın doğu bölümünde, akıntı toprak, yoğun dolgu ve sık bitki örtüsünden dolayı, sadece kıyı yapılarına ve kent suruna ait duvar kalıntıları görülmektedir. Kıyı hattındaki kalıntılara ek olarak, liman alanı kuzey kıyı hattına yakın bir alana dağılmış, moloz taşlardan oluşan dairesel formlu bir kalıntı görülmektedir. Bu kalıntılar aşağıda detaylı olarak ele alınmıştır.

\section{Güney Liman Mendireği}

Liman alanını korunaklı hale getiren mendirek, ana karadan başlayarak yaklaşık 150 metre uzunluğunda ve en geniş yeri yaklaşık 100 metreyi bulan dolgu alanı üzerine inşa edilmiştir (Fig. 3, 4). Mendirek alanı ve alt yapısını oluşturan dolgunun inşasında, akropolisin bulunduğu kayalık alandan kesildiği anlaşılan değişik boyutlardaki moloz taşların kullanıldığı görülmektedir (Fig. 5). Bu dolgu üzerindeki mendireğe ait in-situ ve dağınık haldeki blokların büyük bir bölümü $-0.50 \mathrm{~m}$ ile +0.25 metre derinlikleri arasında, yaklaşık 50x20 metrelik bir alana dağılmıştır (Fig. 6). Doğuda dolgu üzerindeki dörtgen yapıdan güneydoğu doğrultusunda uzanan yaklaşık 4.70 metre genişlikteki mendirek duvarı 18.75 metre düz uzandıktan sonra 52 derecelik açıyla batıya dönerek devam etmektedir. Bu uygulamanın benzerleri Liman Tepe ve Assos liman alanlarında karşımıza çıkmaktadır. Liman Tepe'de mendireğin iç kısmına inşa edilen dalga kıran ile liman alanı dalgalara karşı daha korunaklı hale getirilirken ${ }^{21}$, Phaselis Güney Limanı Mendireği ise Assos'ta ${ }^{22}$ olduğu

20

Schäfer et al. 1981, 50.

21 Erkanal 2008, 181-182, Fig. 3; Erkanal et al. 2017, 140.

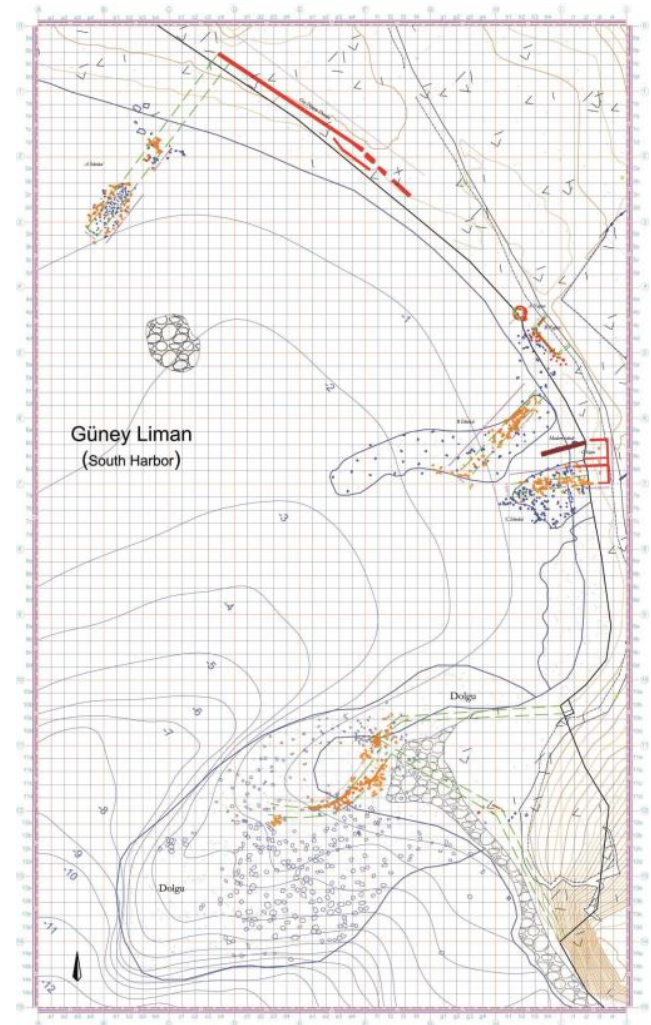

Figür 2. Phaselis güney liman alanı genel planı

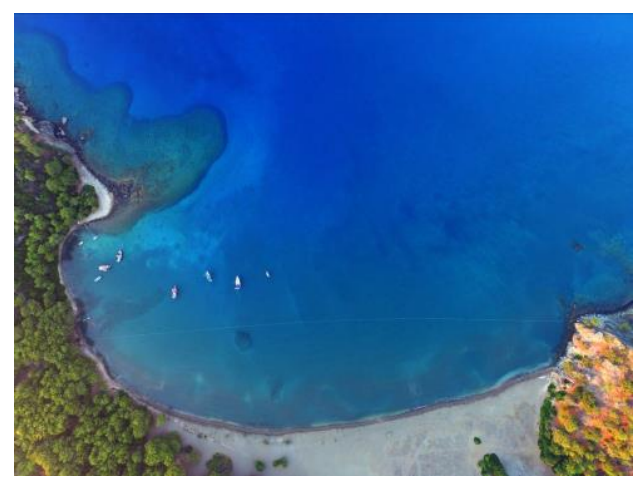

Figür 3. Güney liman alanı hava fotoğrafı 
gibi liman içine doğru döner şekilde inşa edilmiştir. Olasılıkla bu düzenlemeler Klazomenai/Liman Tepe limanı ile aynı amaç doğrultusunda yapıımışıı ${ }^{23}$.

Buna ek olarak batıda yaklaşık $12 \mathrm{~m}$ derinliğe ulaşan mendireğin kıyıya yakın bölümünde dörtgen bir mekânın varlığı dikkat çekmektedir. Mekâna ait dörtgen blokların tuzlu su ve dalgaların aşındırıcı etkisi ile blok görünümünü kaybetmiş olması, işlevinin net olarak anlaşılmasını güçleştirmektedir. Bu mekâna güneydoğudan uzanan sur duvarının bir bölümünün görülmesi, sur duvarının bu alana kadar uzanarak dönüş yaptığını ya da bu alanda yine sura bağlı kule ya da burç olabileceğini düşündürmektedir ${ }^{24}$ (Fig. 4, 6).

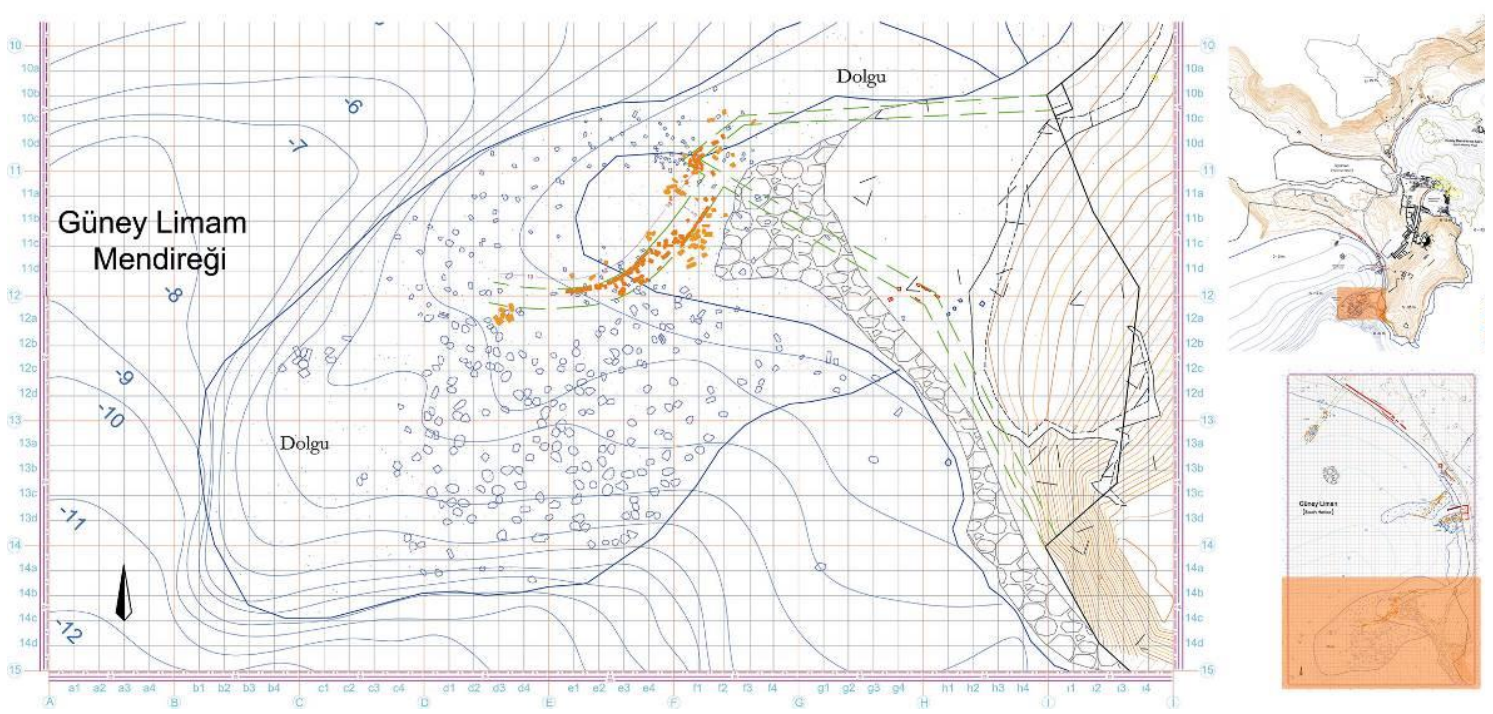

Figür 4. Güney liman mendireği planı

\section{Güney Liman Alanı İskele Yapıları}

Güney Liman alanı içerisinde ikisi doğu, biri kuzey kıyı hattında olmak üzere toplam üç adet iskele yapısı bulunmaktadır. Sığ derinlikte bulunan bu iskelelere ait dörtgen bloklar sualtında dağınık halde bulunmaktadır. Blokların dağınık halde olmaları her ne kadar iskelelerin tam formunun anlaşımasını zorlaştırsa da, in-situ duvar blokları uzandıkları hattın belirlenmesine olanak sağlamaktadır.

Liman alanı kuzey kıyı hattında yer alan ve geç dönem duvarının batı ucundan yaklaşık $40 \mathrm{~m}$ güneybatıda bulunan $A$ iskelesi'ne ait bloklar, aynı doğrultu üzerinde, iki farklı alana dağılmış halde bulunmaktadır (Fig. 2, 7). Kıyıdan yaklaşık $12 \mathrm{~m}$ uzaklıkta $11.40 \times 7.50$ metrelik alanda bulunan bloklar bütünlük göstermezken, yaklaşık 15 m güneybatıda 25.20x12.50 metrelik alan içerisinde yer alan bloklar duvar hattının takibini mümkün kılmaktadır (Fig. 7). Liman alanının güney sınırını oluşturan mendireğin yaklaşık 145 m kuzeydoğusunda, modern ahşap iskelenin yaklaşık $15 \mathrm{~m}$ kuzeybatısında yer alan $B$ iskelesi'ne ait bloklar, hazırlanan karelajda $5 \mathrm{c}-\mathrm{G}$ noktası ile 7-h4 noktası arasında kalan $1500 \mathrm{~m}^{2 \prime \prime l i k}$ alan içerisinde bulunmaktadır. Kıyıdan yaklaşık $15 \mathrm{~m}$ batıdan başlayarak güneybatıya uzanan iskelenin doğrultusunu gösteren in-situ bloklar yaklaşık

22 Assos'ta modern limanın doğusunda yer alan antik limanda hem açı yaparak uzanan mendirek duvarı, hem de mendireğin üzerine oturduğu dolgu alanı Güney Liman Mendireği ile yakın benzerlik göstermektedir. Bkz. Arslan et al. 2017, 72, Res. 14.

23 Erkanal 2008, 181-182, Fig. 3; Erkanal et al. 2017, 140; Şahoğlu 2010, 1571 vd.; Erkanal 2014, 300.

24 Schäfer et al. 1981, 57, Taf. 18.1. 
$13 \times 4$ metrelik bir alanda yer almaktadır (Fig. 8). Kıyı bağlantısını sağlayan blokların başka bir alanda şpolyen olarak kullanıldı̆̆ düşünülmekte, nitekim alanının yaklaşık $15 \mathrm{~m}$ güneydoğusunda yer alan 17.40×1.45 m ölçülerindeki modern ahşap iskelenin altında dörtgen şeklinde düz kesilmiş bloklar kullanıldığı görülmektedir. Göze çarpan bir nokta ise farklı yönlerden liman içerisine uzanmalarına rağmen bu iskelenin $A$ iskelesi ile aynı doğrultuda inşa edilmiş olmasıdır (Fig. 2). Bu planlama incelendiğinde, iskelelerin tamamının kıyıdaki yapılara 90 derecelik açıyla liman içerisine uzatıldığı anlaşımaktadır. Son olarak $B$ iskelesi'nin yaklaşık $23 \mathrm{~m}$ güneydoğusunda ve karelajda $6 \mathrm{c}$-h1 noktası ile $7 \mathrm{~b}-13$ noktaları arasında bulunan $C$ iskelesi'ne ait blokların 600 $\mathrm{m}^{2 \prime}$ lik bir alana dağıldığı görülmektedir (Fig. 8). Sualtında görülebilen düzgün kesilmiş dörtgen bloklar ve kıyıya birleşen noktada kullanılan şpolyen malzemeler (postament blokları, sütun gövdeleri ve çeşitli formlardaki mimari bloklar) ile inşa edildiği anlaşılan iskele yapısına ait sınırlı sayıda in-situ blok bulunmaktadır (Fig. 9) ${ }^{25}$. İskele yapılarına ait sınırlı sayıdaki in-situ bloğun kıyı yapıları ile ilişkisi de göz önüne alındığında genel plan hakkında fikir vermekte ve liman alanı içerisindeki mimari düzenlemenin yorumlanmasına olanak sağlamaktadır.

\section{Güney Liman Kıyı Yapıları}

Liman havzası kıyı hattı boyunca yüzeyde görülebilen yapılar incelendiğinde, doğu kıyı hattı üzerinde yer alan biri yuvarlak formlu olmak üzere toplam üç adet, kuzeyde ise bir adet kıyı yapısı görülebilmektedir. Doğuda yaklaşık $75 \mathrm{~m}$ uzunluğundaki hat üzerinde yer alan üç kıyı yapısı, çalışma kapsamında kuzeyden başlanarak A, B ve C harfleri ile belirtilmiştir (Fig. 8).

Kıyı hattında $A$ iskelesi'nden yaklaşık $30 \mathrm{~m}$ kuzeyde yer alan A yapısı $10 \mathrm{~m}^{2 \prime}$ lik bir alan içerisinde bulunmaktadır. Yuvarlak form gösteren $5.50 \mathrm{~m}$ çapındaki yapının dörtgen bloklarla örülen duvarları, dışta $0.50 \mathrm{~m}$, içte $0.60 \mathrm{~m}$ kalınlıkta örülmüştür. Kıyı hattında yer alan yapının dış duvarı karada $8 \mathrm{~m}$, sualtında ise $5.60 \mathrm{~m}$ uzunlukta takip edilirken, $4.45 \mathrm{~m}$ çapındaki iç duvar ise yoğun moloz ve akıntı toprak altında kaldığından dolayı sadece doğu kısımda az sayıda blok ile takip edilebilmektedir (Fig. 9). Yapı, form ve konum olarak değerlendirildiğinde; iskele yapıları ve kent suruna olan yakınlığından dolayı kule veya fener olabileceği gibi, kıyı hattında bulunan bir sarnıç olması da ihtimaller arasındadır. Ne yazık ki elimizde yapının işlevini ortaya koyabilecek yeterli veri bulunmamaktadır.

Karelajda 4b-h2 ile 5a-ı1 noktaları arasındaki B yapısı, A Yapısı'nın yaklaşık $5.50 \mathrm{~m}$ güneydoğusunda yer almaktadır. Yapının güney limana paralel olarak uzanan güneybatı duvarı $11 \mathrm{~m}$, kuzeybatı duvarı ise batı ucundaki $1.70 \mathrm{~m}$ genişliğindeki kapı açıkığından başlayarak yaklaşık $3.80 \mathrm{~m}$ uzunluğunda günümüze ulaşmışır. Duvar blokları yaklaşık 6 metrelik alana dağıımış haldeki yapının işlevi ve iskele yapısıyla bağlantısı alanda sürdürülecek çalışmalar ile anlaşılabilecek niteliktedir (Fig. 10). Üç odadan oluşan C Yapısı, 6a-ı1 ile 7-ı4 noktaları arasında, $300 \mathrm{~m}^{2 \prime}$ lik alan içerisinde yer almaktadır. 17.30×13.30 metre ölçülerindeki yapının genel planına bakıldığında, liman alanına bakan yüzü haricinde diğer tüm yönlerde yapıyı sınırlayan ve yapı odalarını oluşturan duvarların zemin seviyesinde takip edilebildiği görülmektedir. Günümüzde kullanımına devam edilen ahşap iskelenin bulunduğu alanda olması gereken batı duvarı ise tamamen tahrip olmuştur. Yapıya giriş olasılıkla c odasının güney duvarı üzerindeki 2 metrelik açıklıkla sağlanmaktadır. Bu çok odalı yapı işlevini kaybettikten sonra geç dönem sur duvarının yapı içinden geçerek kıyı hattına ulaştığı görülmektedir.

25 Şipolyen malzeme ile inşa edilen duvar içerisinde yazıtlı bloklarında kullanıldığı görülmektedir. Bkz. TünerÖnen 2015, 24, 31. 


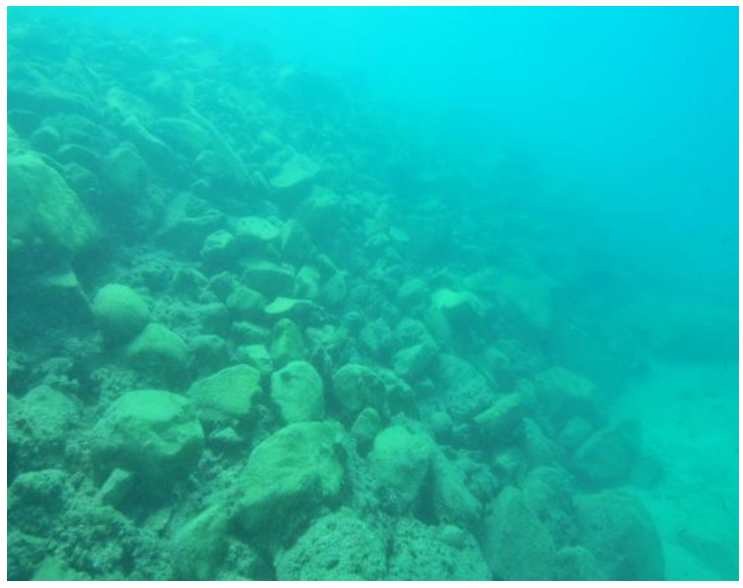

Figür 5. Güney liman mendireği dolgusu sualtından görünüm

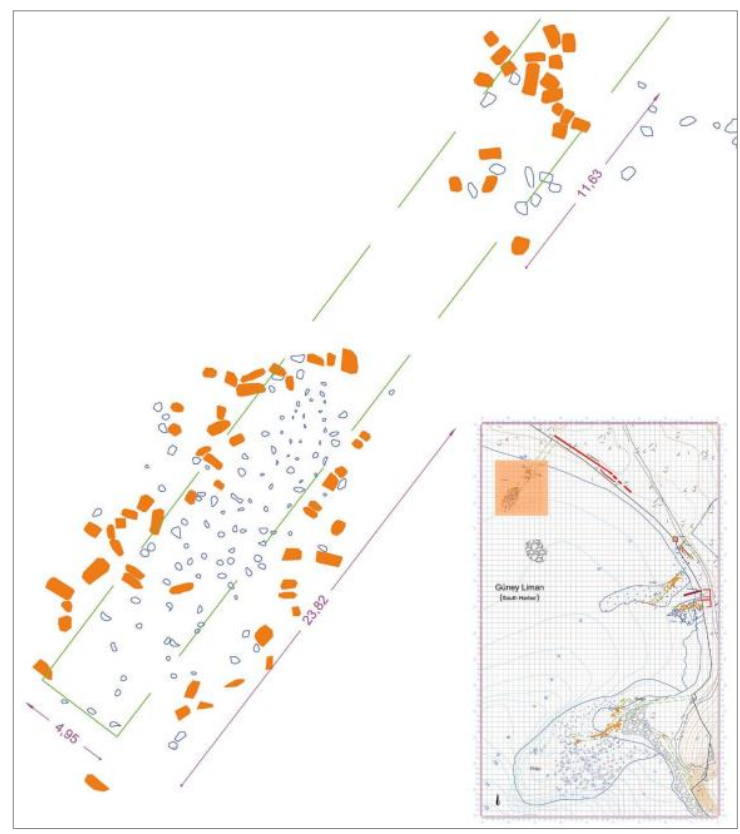

Figür 7. A iskelesi planı

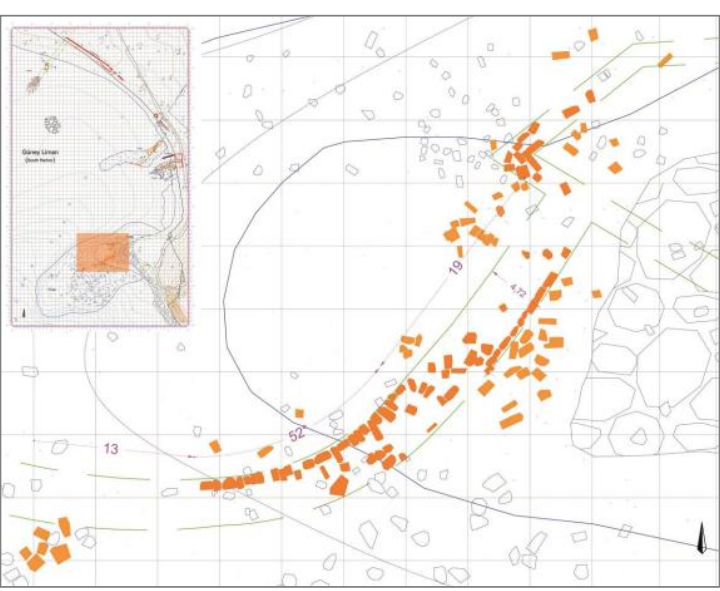

Figür 6. Güney liman mendireği planı

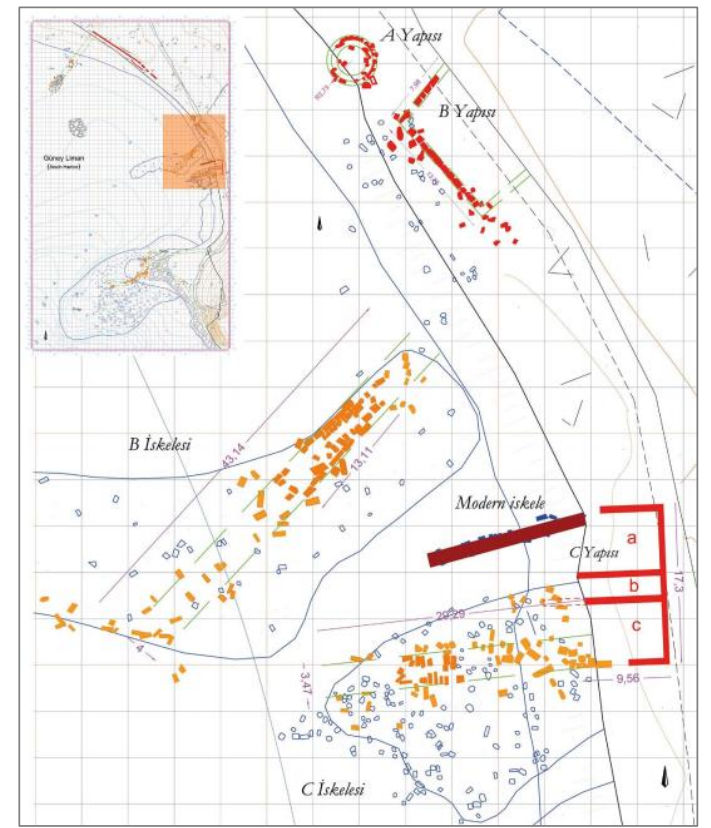

Figür 8. Liman alanı doğu kıyı hattında yer alan yapılar

Kuzeyde kıyı yapısına ait olduğu düşünülen yaklaşık 90 m uzunluğunda, ortalama 1.5 metre kalınlıkta ve örgüsünden geç döneme ait olduğu anlaşılan duvar hattı boyunca herhangi bir dönüş ya da bağlantı noktası görülememekte, olasılıkla bu duvar $A$ iskelesi'nin ulaştığı geç dönem rıhtımı olmalıdır (Fig. 7).

Kıyı yapılarının genel analizi yapılmak istendiğinde, dönemler arasındaki kopukluğun buna izin vermediği görülmektedir. Kent suru ile birlikte ihtiyaç doğrultusunda inşa edilen yapılar, mendireğin dolgusu ve üzerindeki kule yapısı ${ }^{26}$ kentin erken dönemine tarihlenen yapı grubunu oluşturmaktadır. Doğu kıyı hattında yer alan iskelelerin arkasındaki yapı grupları mendirek gibi Roma Imparatorluk Dönemi'ne tarihlenmekte, fakat bu yapılar ile mendirek arasındaki alanda yapı takibinin yoğun bitki örtüsü ve tahribattan dolayı mümkün olmaması, aralarındaki organik bağın tespitini engellemektedir.

26 Schäfer et al. 1981, Taf. 18, 1. 


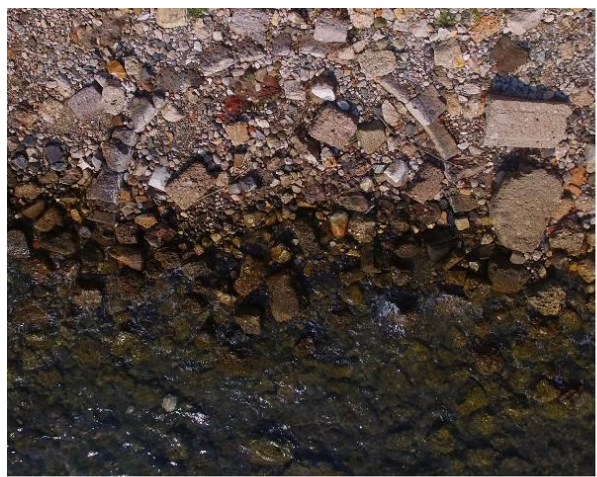

A Yapısı

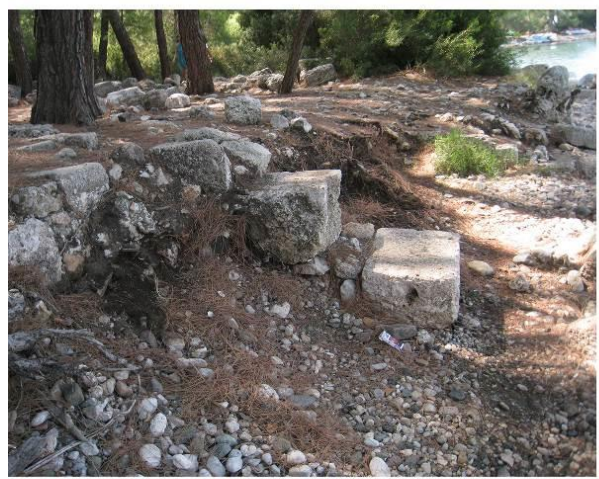

C Yapısı

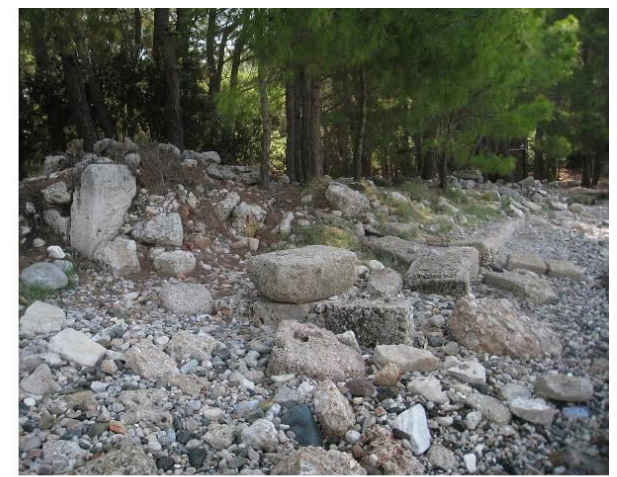

B Yapısı

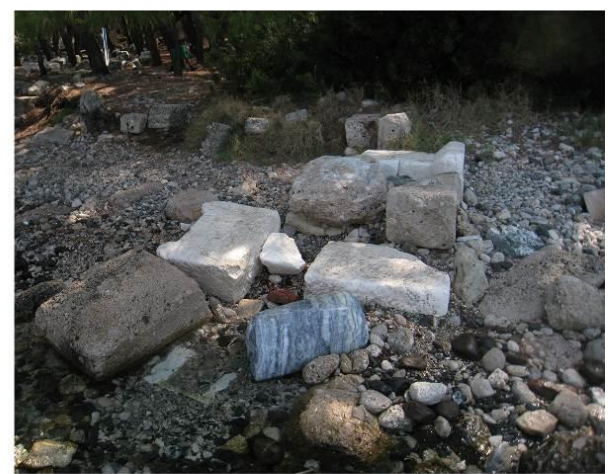

Şpolyen olarak kullanılan mimari bloklar

Figür 9. Liman alanı kıyı yapıları

Güney liman alanı içerisinde kıyı ve iskele yapıları haricinde kuzey kıyı hattına yakın bir alanda bulunan yığıntı farklı bir düzenlemenin belirtisidir. Oldukça sığlık alanda yer alan 20 metre çapındaki döküntünün yaklaşık 35 metre kuzeybatısında $\mathrm{A}$ iskelesi bulunmaktadır. Tam olarak işlevi anlaşılamayan kalıntının liman içindeki konumu ve dağınık olmasına rağmen gösterdiği yuvarlak form, liman faaliyetlerinin savunması ve kontrolü için geç dönemde inşa edilen bir kule ya da fener yapısı olabileceğini düşündürmüştür ${ }^{27}$. Fakat içerisinde düzgün kesilmiş blokların bulunmaması, bu yığıntının buraya yanaşan bir teknenin bıraktığı safraya ait olabileceği önerilmektedir. Geç Antik Çağ'da yapılaşmanın kuzeye kaydığı geç dönem duvar kalıntılarından anlaşımakta, fakat bu alanda herhangi bir kazı çalışması yapılmamış olması, yapı ya da yapı gruplarının işlev ve tarihlendirilmesi hakkında sağlıklı yorum yapmamızı engellemektedir.

\section{Değerlendirme}

Kara ve deniz trafiğinin buluşma noktaları ve kentlerin dış dünyaya açılan kapıları olarak görülen limanlar, kent tarihi ve gelişimi açısından oldukça önemlidir. Kentin liman alanlarından iç limanın oluşumunda tamamen uygun topografik şartlar kullanıımışen, güney liman alanında geniş bir doğal koya yapay mendirekler inşa edilerek liman havzası oluşturulduğu görülmektedir. İhtiyaç ve koşullara göre çeşitlilik gösteren antikite limanları ${ }^{28}$ tipolojik olarak karşılaştırılması zor olsa da kısmen sınıflandırılabilmektedir ${ }^{29}$. Bu sınıflandırmada kıstas olarak işlev ele alınırsa, temelde

\footnotetext{
27 Liman alanında, bu şekilde kıyı yapılarıyla bağlantılı olarak inşa edilen geç dönem örneği olarak lasos Batı Liman girişine inşa edilen kule yapısı gösterilebilir. Ayrıca bk. Baldoni 2010-2011, 285 Fig. 1-2.

28 Aslan 2014, 139.

29 Aslan 2016b, 15-18.
} 
askeri amaçı kullanıldığı düşünülen iç liman, kent limanı ve kuzey limanın aksine kentin ticari faaliyetlerinin Güney Liman alanında yürütüldüğü anlaşılmaktadır. Bu düşüncenin temelinde diğer liman alanlarından farklı olarak, kentin kuzeyinde yer alan sığ ve deniz yüzeyine yakın kayalıkların ve liman havzasının çevresinde falez benzeri sarp kayalıkların bulunmaması yatmaktadır. Bu özelliği ile ticaret gemilerinin yanaşmasına ve ticaret ürünlerinin yüklenmesi ya da boşaltılmasına olanak sağlamaktadır. Güney Limanı'nın bu işlevi tüccarların intiyaçlarını karşılamak için gerekli olan yapıların bu alanda yoğunlaşmasını sağlamışıır ${ }^{30}$. Kıyı hattında yer alan yapıların yoğun tahribi bu alanda olması beklenen rıhtım alanı ve ticari işleve sahip yapıların tamamının tespitini engellemektedir.

Liman alanının tarihlendirilmesi konusunda eldeki bulgular değerlendirildiğinde, kentin erken dönem liman alanlarından biri olduğu ve Geç Antik Çağ'da da kullanımının devam ettiği düşünülmektedir ${ }^{31}$. Sualtında ve kıyı hattında in-situ olarak korunan duvarların özellikleri ve kent surları ile olan organik bağı bu şekilde bir yorum yapmamıza olanak sağlamaktadır. İç Liman gibi olasıııkla kentin kuruluşu ile çağdaş olan Güney Liman alanında, farklı tarihlerde yapılan düzenlemeler net olarak takip edilebilmektedir. Güney liman alanının MÖ VI-IV. yüzyıllar arasında oluşturulduğunu güney sınırı oluşturan dolgu alanı kanıtlamaktadır. Bu tarihlendirme yapılırken liman mendireği neredeyse birebir aynı düzeni gösteren Liman Tepe örneğiyle karşılaştırılmıştır ${ }^{32}$.

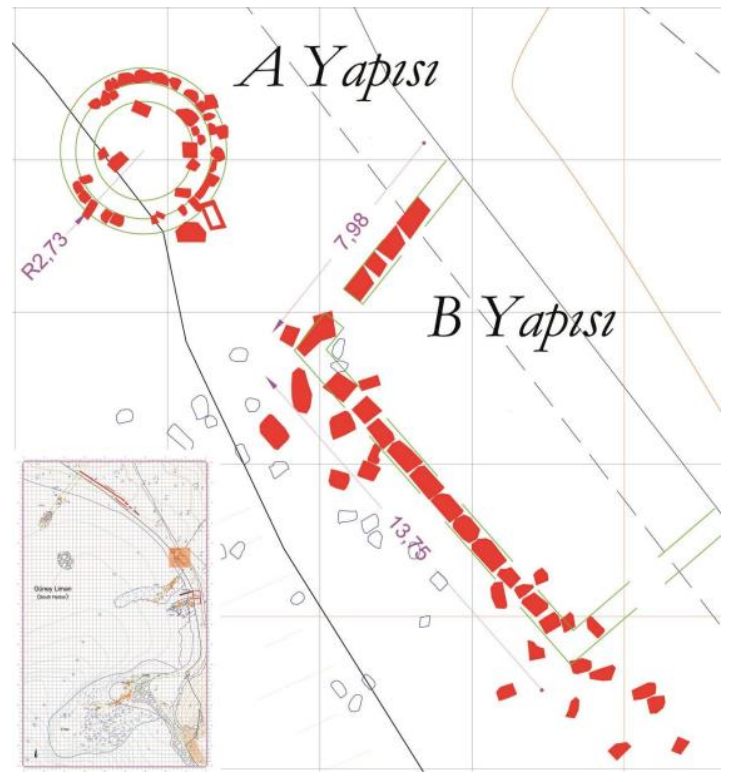

Figür 10. A ve B kıyı yapıları planı

İmparatorluk Dönemi'nde liman alanında yapılan değişiklikler, Hadrianus'un kente gelişi sırasında gerçekleştirilen inşa faaliyetleri kapsamında değerlendirilebilmektedir. Bu dönemdeki inşa faaliyetleri, güney sınırı oluşturan dolgu üzerindeki mendirek duvarı ve Liman Caddesi ile aynı doğrultuda inşa edilen $B$ iskelesi ile takip edilebilmektedir. Bu alandan karaya çıkıldı̆ıında, ithaf yazıtı sayesinde MS 130-131 yıllarında Roma imparatoru Hadrianus onuruna inşa edildiği anlaşılan anıtsal kapıyla karşılaşılmaktadı ${ }^{33}$.

Her iki yapıda görülen benzer duvar işçiliği çağdaş olduklarını düşündürmekte, ayrıca iskele yapısının da mendirek gibi dolgu üzerine inşa edilişi, sadece karaya çıkmak için kullanılan bir yapı

30 Güney limanının ticaret dolayısıyla sahip olduğu önem kıyı hattında yer alan yoğun yapılaşmadan da anlaşılmaktadır. Schäfer burada bir emporion aranabileceğini aktarmaktadır. Bkz. Schäfer et al. 1981, 165.

31 Schäfer et al. 1981, 55-57.

32 Bkz. Şahoğlu 2010, 1571 vd.; Erkanal - Şahoğlu 2012, 228-229; Erkanal 2014, 300; Erkanal et al. 2016, 332$335 ; 2017,144$.

33 Hadrianus'un gerçekleştirdiği Doğu Gezisi sırasında Phaselis, Attaleia ve Perge kentleri, imparatoru karşılamak için ihtişamlı kapılar inşa etmişler ve hem imparatora hem de ailesine ithafen adak heykelleri dikmişlerdir. Tak ve çevresinde bulunan epigrafik veriler değerlendirildiğinde buradaki takın inşası imparatorun 15. tribunica potestas'lığına yani 10 Aralık 130-9 Aralık 131 tarihleri arasına denk gelmektedir. Hadrianus'un kenti ziyareti için inşa edilen kapının limana bakan yüzündeki yazı imparatorun karaya bu alandan çıktığını ve buradaki iskele düzenlemelerinin de aynı döneme tarihlenebileceğini göstermektedir. Bkz. Akurgal 1970, 266; Tüner-Önen 2008, 158, 313-314, 320-321; 2013, 93-106; 2015, 24. 
olmaktan ziyade, ortak bir amaç doğrultusunda yapııdığını düşündürmektedir. Genel plana bakıldığında, dolgu alanının ve mendireğin formu sayesinde, liman alanının güneyinde kapalı bir bölüm oluşturulduğu önerilmektedir ${ }^{34}$. Hadrianus Dönemi inşa faaliyetleri içerisinde değerlendirebileceğimiz bu uygulama ile liman alanı içerisinde yaklaşık $15.000 \mathrm{~m}^{2}$ lik daha küçük ve korunaklı bir alan oluşturarak imparatorun karaya çıkacağı alan, genel ticari faaliyetlerin sürdürüldüğü alandan ayrılmak istenmiş olmalıdır.

Liman alanında görülen Geç Antik Çağ düzenlemeleri ise iki iskele yapısıyla takip edilebilmektedir ${ }^{35}$. Bu iskele yapılarından $A$ iskelesi, kıyıdaki geç dönem duvarıyla muhtemel bağlantısından dolayı liman alanının geç dönem düzenlemeleri arasında değerlendirilmektedir. Kentin geç dönem sur duvarının C Yapısı'nın güney duvarı üzerinden geçerek kıyı hattında bulunan iskeleye bağlanması ve bu alanda kullanılan devşirme malzemeler C iskelesi'nin de Geç Antik Çağ'da kullanılı̆ı̆ını göstermektedir. Olasıııkla Roma Dönemi'nde kullanımda olan doğu kıyı hattındaki $B$ iskelesi'nin herhangi bir nedenle işlevini kaybetmesiyle $A$ ve $C$ iskeleleri inşa edilmiştir. $A$ iskelesi'nin aynı alanın yakınına inşa edilmeyişi, liman zeminin zamanla dolması ya da kıyıdaki yapı merkezinin kuzeye kaymasıyla ilgili olabilir. B İskelesi ile Güney Liman Mendireği'nin güneyde oluşturduğu kapalı alanın benzeri geç dönemde bu iskeleler kullanılarak kuzeyde oluşturulmuş olabilir. Bu planlamanın tipoloji olarak örtüşüp örtüşmediği yeterli verinin bulunmayışından dolayı açıklanamamaktadır. Ancak iskelelerin benzer dağınık örgüsü ve aralarında bulunan yuvarlak formlu kalıntının yapı olduğu düşünülürse, Geç Antik Çağ’da liman içerisinde daha küçük bir liman oluşturulduğu önerilebilir. Geç Antik Çağ’da buradaki iskele üzerinden kentin ticari faaliyetlerini sürdürmüş olduğu düşünülmektedir. Fakat bunu belgeleyecek kanıtlayıcı veriler alanda yapılacak kazı çalışmalarıyla elde edilebilecek niteliktedir.

34 Bu uygulamaya örnek olarak Kenkhreai limanı gösterilebilir. Bkz. Shaw 1972, Fig. 8.

35 Ayrıca mendirek altındaki dolgu ve çevresinde yapılan sualtı araştırmalarında tespit edilen çatı kiremidi, künk parçaları ve form veren amphora parçaları yaptığımız tarihlemeyi desteklenmektedir. MS I-II. yüzyıllar arasına tarihlenen AE-3 amphora tipi mendireğin inşa tarihiyle ilişkilendirilirken, LR-4, LR-1C, LR-2C amphoraları limanın geç dönemde kullanımının sürdürüldüğünü göstermektedir: Orhan 2017, 141 vd. 


\section{BIBLIYOGRAFYA}

\section{Antik Kaynaklar}

Strab.

Plin.

Thuk.

Plut. Aleks.

Liv.

(= Strabon, Geographika)

Kullanılan Metin ve Çeviri: Strabo, The Geography of Strabo. Trans. H. L. Jones. London-New York 1961 (The Loeb Classical Library).

(= Plinius, Naturalist Historiae)

C. Plini Secundi, Natualis Historiae, Libri XXXVII. Vols. 1-5. Ed.: C. Mayhoff, 1892-1902.

(= Thucydides, History of the Peloponnesian War)

Kullanılan Metin ve Çeviri: Thucydides, History of the Peloponnesian War, Vols. I-IV. Trans.: C. F. Smith. London 1919-1923 (The Loeb Classical Library).

(= Plutarkhos, Bio Paralleloi, Aleksandros)

Kullanılan Metin ve Çeviri: Plutarch's Lives, Vols. I-XI. Ed. \& Trans.: B. Perrin. London-New York 1959 (The Loeb Classical Library).

(= Livius, Ab Urbe Condita)

Kullanılan Metin ve Çeviri: Livy, From the Founding of the City. Trans.: A. C. Schlesinger. London-New York 1967 (The Loeb Classical Library).

\section{Modern Kaynaklar ve Kısaltmalar}

$A A$

Adalya

AJA

Akurgal 1970

Arslan 2003a

Arslan 2003b

Arslan 2012

Arslan 2018

Arslan - Tüner Önen 2011

Arslan et al. 2013

Arslan - Tüner Önen 2013

Arslan et al. 2017

Aslan 2014

Aslan 2016a

Aslan 2016b

Aslan - Baybo 2015

Aygın 2017

Baldoni 2010-2011
Archäologischer Anzeiger.

Annual of the Suna \& Inan Kiraç-Research Institute on Mediterranean Civilizations.

American Journal of Archaeology. Boston.

E. Akurgal, Ancient Civilizations and Ruins of Turkey. Ankara 1970.

M. Arslan, “i.Ö. 188 Yılından İ.Ö. 67 Yılına Kadar Lykia, Pamphylia ve Kilikia Trakheia Sahillerindeki Korsanlık Faaliyetleri: Nedenleri ve Sonuçları". Adalya VI (2003) 91-118.

M. Arslan, "Piracy on the Southern Coast of Asia Minor and Mithridates Eupator". OLBA VIII (2003) 195-211.

M. Arslan, "Pseudo-Skylaks: Periplous". MJH II/1 (2012) 239-257.

M. Arslan, "Phaselis ve Teritoryumunun Yol ve Savunma Sistemleri: Tekirova-Çamyuva Arası". Phaselis IV (2018) 15-47.

M. Arslan - N. Tüner Önen, "Akdeniz'in Korsan Yuvaları: Kilikia, Pamphylia, Lykia ve Ionia Bölgelerindeki Korykoslar". Adalya XIV (2011) 189-206.

M. Arslan, K. Demirtaş - N. Tüner Önen, "Phaselis ve Teritoryumu Yüzey Araştırması 2012". Anmed 11 (2013) 224-229.

M. Arslan - N. Tüner Önen, "2012 Yılı Phaselis Antik Kenti ve Teritoryumu Yüzey Araştırması". AST 31/1 (2013) 78-89.

N. Arslan - B. Arslan - C. Bakan - K. Rheidt - J. Engel, "Assos Kazısı 2015 Yılı Sonuç Raporu". KST 38/3 (2017) 53-72.

E. Aslan, "Bithynia Bölgesi Kalpe Limanı". OLBA XXII (2014) 129-154.

E. Aslan, "Phaselis Merkezi (Kent) Limanı". Phaselis II (2016) 31-47. DOI: 10.18367/Pha.16003

E. Aslan, Kekova Bölgesi Limanları. Konya 2016.

E- Aslan - S. Baybo, "Phaselis Kent Limanları ve Sualtı Araştırmalarının Ön Değerlendirmesi". Phaselis I (2015) 1-17. DOI: 10.18367/Pha.15001.

Ç. A. Aygın, Andriake Mureks Boya Endüstrisi. Adalya Ek Yayın Dizisi 14, İstanbul 2017.

D. Baldoni, "Materiali Dallo Scavo Della Torre Del Porto Occidentale Di 
Balland 1981

Bass 1961

Bass et al. 1967

Bass 1986

Bean 1968

Beaufort 2002

Blackman 1973

Blackman 1981

Blackman 1982

Blackman 2008

Bryce 1986

Casson 2002

DOP

Erkanal 2008

Erkanal 2014

Erkanal - Şahoğlu 2012

Erkanal et al. 2016

Erkanal et al. 2017

Foss 1994

Frei 1993

Gerkan 1959

Heipp-Tamer 1993

IJNA

IstMitt

Jameson 1973

Kolb - Kupke 1992

KST

\section{Erdoğan ASLAN - Yusuf KILIÇ - Uğurcan ORHAN}

Iasos". Atti Dell' Accademia Delle Scienze Di Ferrara Vol. 88 (2010-2011) 285-318.

A. Balland, Inscriptions d'époque impériale du Létôon. Fouilles de Xanthos 7, Paris 1981.

G. F. Bass, "The Cape Gelidonya Wreck: Preliminary Report". AJA 65/3 (1961) 267-276.

G. F. Bass, P. Throckmorton, J. D. P. Taylor, J. J. Hennessy, A. R. Schulman, H-G. Buchholz, "Cape Gelidonya: A Bronze Age Shipwreck". Transactions of the American Philosophical Society 57/8 (1967) 1-177.

G. F. Bass, "A Bronze Shipwreck at Ulu Burun (Kas): 1984 Campaign". AJA 90/3 (1986) 269-296.

G. E. Bean, Turkey's Southern Shore. London 1968.

F. Beaufort, Karamanya. Çev. A. Neyzi-D. Türker, Antalya 2002.

D. J. Blackman, "The harbours of Phaselis". IJNA 2/2 (1973) 355-364.

D. J. Blackman, "Brief History of the City, based on the Ancient Sources". Ed. J. Schäfer, Phaselis. Tubingen (1981) 31-37.

D. J. Blackman, "Ancient Harbours in the Mediterranean 2". IJNA 11/3 (1982) 185-221.

D. J. Blackman, "Sea Transport, Part 2: Harbors". Ed. J. P. Oleson. The Oxford Handbook Engineering and Technology in The Classical World, Oxford (2008) 638-670.

T. R. Bryce, The Lycians in Literary and Epigraphic Sources. Copenhagen 1986.

L. Casson, Antik Çağda Denizcilik ve Gemiler. Çev. G. Ergin. İstanbul 2002. Dumbarton Oaks Papers.

H. Erkanal, "Liman Tepe: A New Light on the Prehistoric Aegean Cultures". Eds. H. Erkanal, H. Hauptmann, V. Şahoğlu, R. Tuncel, The Aegean in the Neolithic, Chalcolithic and the Early Bronze Age. Ankara (2008) 170-190.

H. Erkanal, "Klazomenai/Liman Tepe'nin Limanları". Byzas 19-1 (2014) 295-304.

H. Erkanal - V. Şahoğlu, "Liman Tepe (1992- )". DTCF 75. Yıl Armağanı DTCF Arkeoloji Bölümü Tarihçesi ve Kazıları (1936-2011). Ankara (2012) 219-230.

H. Erkanal, A. Aykurt, K. Büyükulusoy, I. Tuğcu, R. Tuncel, V. Şahoğlu, "Liman Tepe 2014 Yılı Kara ve Sualtı Kazıları". KST 37/1 (2016) 323-340.

H. Erkanal, A. Akyurt, K. Büyükulusoy, i Tuğcu, R. Tuncel, V. Şahoğlu, "Liman Tepe 2015 Yılı Kara ve Sualtı Kazıları". KST 38/3 (2017) 133-150.

C. Foss, "The Lycian Coast in the Byzantine Age". DOP 48 (1994) 1-52.

P. Frei, "Solymer, Milyer, Termilen, Lykier, Ethnische und politische Einheiten auf der lykischen Halbinsel". Akten Lykien 2/1 (1993) 87-97.

A. V. Gerkan, Von Antike Architektur und Topographie: Gesammelte Aufsätze. Eds. A. v. Gerkan, E. Boehringer. Stuttgart 1959.

C. Heipp-Tamer, Die Münzprägung der lykischen Stadt Phaselis in griechischer Zeit. Saarbrücken 1993.

The International Journal of Nautical Archaeology and Underwater Exploration.

Istanbuler Mitteilungen.

S. Jameson, "Lykia". RE Suppl. 13 (1973) 265-308.

F. Kolb - B. Kupke, Lykien. Geschichte Lykiens im Altertrum. Mainz 1992.

Kazı Sonuçları Toplantısı. 
Lehmann- Hartleben 1923

Magie 1950

Marek 1995

$\mathrm{MJH}$

Müller 2010

OLBA

Orhan 2017

$R E$

RNum

Schäfer et al. 1981

Schläger - Schäfer 1971

Seyrig 1963

Shaw 1972

Stark 1956

Şahoğlu 2010

Robert 1966

Tüner Önen 2008

Tüner Önen 2012a

Tüner Önen 2012b

Tüner Önen 2013

Tüner Önen 2015

Zimmermann 1992a

Zimmermann 1992b

ZPE
K. Lehmann - Hartleben, Die antiken Hafenanlagen des Mittelmeeres. Leipzig 1963.

D. Magie, Roman Rule in Asia Minor I-II. Princeton 1950.

C. Marek, "Der Lykische Bund, Rhodos, Kos und Mithridates: Basis mit Ehreninschrift für Krinolaos, Sohn des Artapates, von Patara". Lykia II (1995) 9-21.

Mediterranean Journal of Humanities.

K. Müller, "Anonymi Stadiasmus Maris Magni". Ed. K. Müller, Geographi Graeci Minores. Cambridge (2010) 427-514.

Mersin Üniversitesi Kilikya Arkeolojisini Araştırma Merkezi yayınları.

U. Orhan, "Phaselis 2016 Yılı Güney Limanı Amphora Buluntuları". Phaselis III (2017) 141-148.

Paulys Realencyclopädie der classischen Altertumswissenschaft.

Revue numismatique.

H. Schläger, D. J. Blackman, H. Bremer, J. Christern, P. Knoblauch, J. Schäfer, "Phaselis Beiträge zur Topographie und Geschichte der Stadt und ihrer Häfen". Ed. J. Schäfer. IstMitt. 24 (1981).

H. Schläger, J. Schäfer, "Phaselis Zur Topographie Der Stadt und Des Hafengebietes". AA 86 (1971-1972) 542-561.

H. Seyrig, "Monnaies hellénistiques". RNum 5 (1963) 7-64.

J. W. Shaw, "Greek and Roman Harbours". Ed. G. F. Bass, A history of seafaring based on underwater archaeology. London (1972) 87-112.

F. Stark, The Lycian Shore. London 1956.

V. Şahoğlu, "Ankara Universty Research Center for Maritime Archaeology (ANKÜSAM) and its Role in the Protection of Turkey's Underwater Cultural Heritage". Proceedings of the World Universty Congress, Çanakkale 20-24 October 2010/2 (2010) 1571-1580.

L. Robert, Monnaies antiques en Troade. Geneve 1966.

N. Tüner Önen, "Phaselis Antik Kenti ve Teritoryumu. Yayımlanmamış Doktora Tezi". Akdeniz Üniversitesi. Antalya 2008.

N. Tüner Önen, "Ideas Concerning the Historical Identity and the Connections of the City of Phaselis an Eastern Mediterranean Port". MJH II/1 (2012) 205-22.

N. Tüner Önen, "Yazıtlar Işığında Phaselis". Eds. K. Dörtlük, T. Kahya, R. Boyraz-Seyhan, T. Ertekin, Uluslararası Genç Bilimciler Buluşması I: Anadolu Akdenizi Sempozyumu 04-07 Kasım 2009. Akmed (2012) 479-488.

N. Tüner Önen, "Hadrians Reisen im Östlichen Mittelmeer Anhand Neuer Inschriften aus Phaselis". Adalya XVI (2013) 93-106.

N. Tüner Önen, "Yeni Buluntular Işığında Phaselis Epigrafi Çalışmaları". Phaselis I (2015) 19-38.

M. Zimmermann, "Die Lykischen Häfen und Handelswege im Östlischen Mittelmeer". ZPE 92 (1992) 201-217.

M. Zimmermann, Untersuchungen zur Historischen Landeskunde Zentrallykiens. Bonn 1992.

Zeitschrift für Papyrologie und Epigraphik. 